\title{
“GATO, CACHORRO E CRIANÇA - É O QUE MAIS TEM NA FAVELA": DIMENSÕES DO TRABALHO
}

\section{Antônio Donizeti Fernandes ${ }^{1}$}

\section{A escuta e a escrita biográfica}

A experiência social ${ }^{2}$ - no que diz respeito à dimensão da ordem vivida pelos trabalhadores canavieiros, assim como a tem todos os homens e mulheres das demais categorias ocupacionais - ao sentirem e vivenciarem de maneira emocional- as experiências estéticas, amorosas ou religiosas - corresponde à capacidade de lidar com a subjetividade e à identidade, isto é, à totalidade coletiva como consciência de si frente ao "outro". Experimentam estes homens e mulheres, consigo mesmos e com os outros sujeitos $^{3}$, o mundo não simplesmente enquanto estrutura estruturada ${ }^{4}$, mas a sua interpret(ação) por meio de categorias sociais, tal como a frase que ouvi pela primeira vez, estando no lugar em que realizei as minhas investigações sobre a questão do trabalho "fora do mundo do trabalho" e que se apresenta como subtítulo deste artigo. O mundo da vida ${ }^{6}$ - "gato, cachorro e criança: é o que mais tem na favela" - propõe pistas sobre os sentidos do habitar entre aqueles que se encontram destituídos e muito próximos dos excessos da má qualidade de vida. Propõe como problemática que se retome a consciência que os sujeitos sociais possuem a respeito de si mesmos ${ }^{7}$ ao viverem, a partir da condição de verem-se entre o talhão de cana e a favela, a rotina dos encontros enquanto mundo em comum que se experimenta a partir de situações que evocam a noção de experiência social negativa, o diverso do normal - o que foi construído pelo "outro" - o local privilegiado da diferença e da desigualdade social.

Apresento com esta escrita as tensões, os apoios e as negociações ocorridas, tendo no testemunho biográfico dos trabalhadores, frente as suas trajetórias busca por trabalho

\footnotetext{
${ }^{1}$ Universidade Estadual do Norte do Paraná, Brasil

2 (Lebarón, 2009: 57)

3 (Jodolet, 2005: 31-32)

${ }^{4}$ As escolas linguística e antropológica, representadas por Saussure e Lévi-Strauss - seguidores da obra de Durkheim e a crítica ao objetivismo. (Ortiz, 1983: 11)

${ }^{5}$ (Fernandes, 2012)

${ }^{6} \mathrm{O}$ mundo da vida cotidiana significa o mundo da intersubjetividade. Um estoque de experiências que funciona como um código de referência (Schütz, 1979: 72).

${ }^{7} \mathrm{O}$ mundo cotidiano apresenta-se como de interesse, eminentemente, prático e não teórico. Válido e comum, também, ao cientista social (Schütz, 1979; 1972: 39-40).
} 
e moradia, as relações e as experiências interpessoais que propõem ou correspondem a algo que esses sujeitos fizeram juntos ${ }^{8}$.

Mostro a partir da ideia de técnica da conversa cotidiana, a maneira como procedi para captar, interpretar e analisar categorias nativas que me possibilitaram compreender o sentido do sofrimento social vivido por aqueles que tendem a ser vistos como fósseis vivos ou mesmo como refugo. Portanto, a partir da ideia de sentido comum em face de assuntos essenciais como trabalho e moradia, o que está em jogo com esta escrita corresponderia à descrição do conhecimento prático frente àquilo que se supõe, antecipadamente, ao se lidar com a necessidade em sua diversidade.

É nesse sentido que se pode dizer que o sofrimento, a partir de novas formas de dominação, mostra-se como uma condição situacional compartilhada - enquanto experiência social negativa -, cuja expressividade manifesta-se sob o impacto da reestruturação das relações de trabalho e de produção da cultura agrocanavieira. Nesse aspecto as usinas locais de açúcar e álcool ${ }^{9}$, enquanto expressões simbólicas e materiais destas formas e práticas de dominação, a partir dos anos de 1980, vêm ajustando-se ao novo padrão de racionalidade de reprodução ampliada do capital de modo a combinar velhas e novas práticas de controle da força de trabalho.

Do ponto de vista da descrição etnográfica em minha tentativa de compreender os sentidos da sociabilidade a partir do sofrimento, tendo em cona tais formas de relações de dominação, é que compartilho da seguinte perspectiva teórico- metodológica:

\begin{abstract}
Nossa intenção é dissolver a dicotomia individual/coletivo. Experiência interpessoal é a área da mediação sociosomática [...]. No campo local da experiência, as amostras de processos unificados de memória, a influência, e a fisiologia podem ser descritas como uma variedade dos níveis: pessoal, familiar, rede, a comunidade. Contudo é a ideia nova da experiência como um meio interpessoal da mediação que nós desejamos sublinhar, antes que sua mais usual categorização como uma forma pessoal. Por essa razão, nós descrevemos nossa abordagem como a etnografia da experiência interpessoal, embora talvez nós pudéssemos, igualmente bem, descrevêla como sociodinâmicas da experiência cultural, porque constitui por meio dos
\end{abstract}

\footnotetext{
8 “[...] o conhecimento não é uma coisa que as pessoas possuem na cabeça, mas algo que elas fazem juntas" (Spink, 1999: 76). E ainda que guardem posições diferentes, na maneira como interpretam a relação entre ação e estrutura, poder-se-ia dizer que (Giddens, 2003) e (Bourdieu, 2000; 2007) mantém em comum a noção de que o conhecimento corresponda a um conhecimento, antes de tudo, prático.

9 No Paraná as empresas sucroalcoleiras em sua totalidade estão localizadas ao norte do Estado e, em 2010, somavam-se perto de 35 unidades. A maioria destas empresas, tanto no norte paranaense como no oeste paulista - com cerca de 20 unidades - projetaram as suas instalações ao longo do Rio Paranapanema. Localizada na margem paranaense do Médio Vale do Paranapanema, os municípios de Jacarezinho, Cambara e Bandeirantes mantêm, atualmente, cerca de 4 empresas sucroalcoleiras em oposição a margem paulista com cerca de 11 usinas de álcool e açúcar.
} 
processos e das práticas das rotinas interpessoais e dos ritmos da experiência ${ }^{10}$. (tradução nossa)

O sofrimento enquanto experiência social, por essa perspectiva, permite retomar a ideia de reciprocidade de expectativas ${ }^{11}$, a partir daquilo que comum se tornou por apresentar-se como algo interpessoal e intersubjetivo. Assim, por mais íntimo que se apresente a dor, enquanto expressão do sofrimento, esta se encontraria impregnada de material social, cultural e relacional ${ }^{12}$, pois tal estado exige sentido em face das experiências que se traduzem a partir das práticas sociais.

Neste aspecto, estando na favela uma das coisas que pude perceber e que mais me chamou a atenção, foi o fato de poder participar sem muitos esforços da intimidade de meus vizinhos e de que as minhas expectativas eram poder transformar - sob o aspecto do uso dos equipamentos fotográficos - as cenas e relatos, outros, que viesse registrar em materiais que me possibilitassem a escuta da consciência discursiva acerca da experiência vivida, assim como a escuta de minhas próprias preocupações e procedimentos na operacionalização da pesquisa.

$\mathrm{Na}$ ocasião do trabalho de campo, lembrei-me sobre o fato de que em antropologia tudo estar fundado na alteridade e de só existir o antropólogo se houver nativo transformado em informante ${ }^{13}$, assim como, somente haver dados se houver empatia entre o pesquisador e os nativos. Mas, estando imerso na ânsia de ser aceito na favela e por mais estranho que me sentisse, o esforço para não esquecer-me dessa condição de papel participante-como-observador ${ }^{14}$ atenuava por demais a reflexão sobre o desafio da proximidade, talvez nem tanto pela busca por interiorizar o ato de transformar o familiar em estranho e o estranho em familiar e sim, pela própria condição da duração da experiência vivida ${ }^{15}$.

\footnotetext{
${ }^{10}$ (Kleinman, 1995: 272)

11 “Os homens nunca têm, seja lá no que forem experiências idênticas, mas supõem que elas sejam idênticas, fazem como se fossem idênticas, para todos os fins práticos. A experiência subjetiva de um indivíduo é inacessível a outro indivíduo. Os próprios atores ordinários, que no entanto não são filósofos, sabem que não veem jamais os mesmos objetos[...]. Ninguém vê a mesma coisa, quando vai assistir a uma partida de futebol, quer esteja sentado nas tribunas centrais quer nas arquibancadas [...]. No entanto estarão todos de acordo em dizer que todos os espectadores acompanharam a mesma partida" (Coulon, 1995: 12-13)

12 (Le Breton, 1999); (Berger; Luckmann, 2004)

${ }_{13}^{13}$ (Da Matta, 1978)

14 (Cicoure, 1975)

15 Talvez por isso, conforme (Da Matta, 1978), as anedotas, a falta de contato e a ignorância do etnógrafo sejam um dos principais caminhos do estranhamento em antropologia ao buscar a reconstituição da realidade vivida. E a concordar com (Shütz,1972: 63): "Somente o que já foi vivenciado é significativo, e não aquilo que está sendo vivenciado. Pois o significado é meramente uma operação da intencionalidade, a qual, no entanto, só se torna; visível reflexivamente. Do ponto de vista da experiência que está se
} 
E por isso, só na distância da experiência vivida, a escrita do relato se transforme em uma interpretação dos textos sociais trazidos do campo pelo investigador. Assim, sob a tentativa do difícil resgate do clima da situação encontrada em seu vínculo com a teoria, a escrita etnográfica - embora privilegiando o retrato integrado - ainda que deixando de lado, quase sempre, os autores e atores sociais ${ }^{16}$. No caso desta pesquisa, o dono da casa em que me alojei, ao me apresentar os seus antigos vizinhos e conhecidos, por assim dizer, acabou por se tornar em meu principal informante, não só em relação aos moradores da vila Santa Gertrudes, mas também à conexão com os amigos de botequim e de seus familiares que se encontravam, em parte, fora dos limites do conglomerado de casas da favela onde ele morou por quase vinte anos. No labirinto da favela ${ }^{17}$ o ex-empreiteiro guiou e apresentou-me aos antigos moradores e, talvez por desconhecer, não pôde fazer o mesmo com relação aos novos residentes em seu trânsito e na sua movimentação mais furtiva ${ }^{18}$, o que me levou a esquecer, por um momento que estar "de perto" e "de dentro" da favela, do bairro ou do talhão de cana correspondia a inscrever-me em uma ordem relacional dada a partir da circulação de poder e de seu exercício, muito embora, logo fosse lembrado sobre essa condição.

O território e o espaço não são idênticos, tampouco, correspondem a um lugar estritamente físico ${ }^{19}$. Por essa perspectiva o território da favela localizada na vila Santa Gertrudes, poder-se-ia mesmo dizer, em sua instalação e apropriação propunham um conhecimento prático relacional dos atores ao lidarem com uma multidimensionalidade interagida $^{20}$, ou seja, a produção de práticas sociais e sua inscrição como um campo de poder e de dominação, dada à forma particular como se territorializa o espaço.

passando, a predicação de significado é, necessariamente, trivial, já que significado, aqui, só pode ser entendido como um olhar atento dirigido não à experiência que está passando, mas à experiência já passada".

${ }^{16}$ (Clinfford, 2002: 42)

17 A primeira vez que tomei contato com a representação da favela, como labirinto, ocorreu logo após o meu reencontro com um dos primeiros moradores que entrevistei e que me perguntou se já havia compreendido o seu enigma, mas até então, nem me atinava para o fato de que também é no labirinto que se encontra o Minotauro, conforme o mito grego, e que ele poderia estar encarnado na figura do traficante: um aviso? (Jacques, 2007: 73).

${ }^{18} \mathrm{O}$ ex-empreiteiro, em face da maneira como interagia na favela, pareceu-me, em um primeiro momento, não ter "[...] mais posições a defender ou [...] [se sentir] ameaçado por expor o que os outros dizem ou fazem" (Dean, 1955, apud Cicourel, 1975: 113). Em uma das conversas primeiras que mantive com uma moradora vizinha, ela me confidenciou sobre a movimentação contínua na favela e de que ali havia pessoas de todos os lugares, mas que, ultimamente, muitas vinham de cidades do interior paulista, tais como aqueles provindos de Sorocaba e que, dentre os novos abrigados, inclusive, havia um foragido da polícia.

${ }^{19}$ (Raffestin, 2011)

20 “O território se dá quando se manifesta e exerce-se qualquer tipo de poder, de relações sociais. São as relações que dão o concreto ao abstrato, são as relações que consubstanciam o poder. Toda relação 
Aos poucos ia explorando, assim, os limites de algumas ruelas da favela na ida e vinda ao Centro de Referencia em Assistência Social - CRAS -, visitas à casa da mãe de meu principal informante, bem como, os pontos de saída para o talhão de cana. Estabeleci, durante o dia, um percurso em que pudesse observar e ser observado por aqueles que, por algum motivo, não se encontravam no trabalho e, à noite no Bar Amigos da Viola, procurei por possíveis aspectos e indicações de tais relações, a partir do trajeto de seus frequentadores - cortadores de cana, aposentados, operadores de máquinas, empreiteiros, pedreiros e desempregados. Deparei-me com pessoas de olhares curiosos e aparência septuagenária à beira de fogões a lenha, cuidando de crianças e da limpeza dos quintais ${ }^{21}$, assim como, a presença de adolescentes postados ao longo desses caminhos como que guardando o lugar ou algo parecido tanto de dia como à noite. Desde o início do trabalho de campo, mesmo que não fosse para fazer uso, sempre que pude apresentei-me com uma máquina de filmar e, intimamente, a me perguntar sobre o que registrar em relação ao que via e o que poderia ouvir. Nesse sentido, estar com uma filmadora à mão era uma maneira de apresentar e de lembrar sobre os motivos de estar ali, bem como, possibilitava-me observar a reação das pessoas em face daquilo que poderia ou não ser visto. Em uma das apresentações feitas pelo meu guia, ao explicar para alguns vizinhos os motivos de minha pesquisa, reconheci um rapaz branco, de vinte e cinco a trinta anos, que avistei em minhas primeiras explorações no bairro, cuja, qualidade e o uso da roupa que trajava ao estilo hip-hop, distinguiam-no dos demais jovens avistados. Mas foi ao me aproximar, que pude ouvir e perceber o grau de desconfiança em relação ao estranho, bem como, as primeiras explicações das pessoas sobre minha presença na favela ${ }^{22}$. Já nas proximidades do Bar do $\mathrm{Julho}^{23}$, localizado a poucos metros de meu abrigo, uma das primeiras impressões que tive foi a de que, por mais que falasse ninguém iria entender ou acreditar no que

social,econômica, política e cultural é marcada pelo poder, porque são relações que os homens mantêm entre si nos diferentes conflitos diários” (Saqued 2003, apud Eduardo, 2006: 176).

${ }^{21}$ Alguns desses abrigos, inclusive, mantinham em comum a inscrição XR grafada em suas paredes, isto é, a indicação da demolição e transferência dos moradores para um novo conjunto habitacional que estava sendo construído no bairro.

${ }^{22}$ A presença do pesquisador no campo e a sua explicação aos nativos (Foote-Whyte, 1975); a etnografia como uma negociação construtiva (Clifford, 2002: 43)

${ }^{23}$ No bar do Julho, o dono do estabelecimento, após saber que estava na vila para fazer uma pesquisa, perguntando-me se jogava futebol, de imediato, pediu-me que comprasse uma bola para o time, ao que respondi dizendo que o faria, mas que naquele momento estava sem dinheiro e que tinha que acertar algumas contas. Logo após esse comentário, percebi certa indignação, ao mesmo tempo em que ficou evidente que as pessoas procuravam se informar sobre quem eu era, pois, conforme o comerciante, ele não acreditava que alguém morando em um bairro melhor situado, não tivesse condições de comprar uma bola de futebol. Dizer, como argumento que a minha casa se encontrava em uma vila vizinha, não minorou o desfecho que se desenhava em relação a minha presença na comunidade 
dissesse, tanto que Dagão, o rapaz a quem fui apresentado e que anteriormente havia avistado, sentindo-se muito desconfiado e mesmo incomodado ainda que a filmadora se mantivesse desligada, de imediato perguntou-me se era jornalista, pois, para ele, o que não faltava eram pessoas interessadas em difamar a favela. Disse-lhe então que estava ali para saber sobre como era o cotidiano vivido dos trabalhadores do corte de cana, pois iria escrever um livro sobre as situações relacionadas a infortúnios, acidentes, contratação dos trabalhadores, moradia, ritmo de trabalho, mas, avistando outro rapaz e interrompendo-me, já na entrada do bar, após os cumprimentos, confiou-me Dagão, que não queria trabalhar mais como canavieiro e, voltando-se para o conhecido ao lado, em proveito do assunto, perguntou-lhe sobre a possibilidade de fazer um teste para o emprego de tratorista onde o amigo trabalhava. $\mathrm{O}$ homem negro, aparentando ter entre trinta e cinco a quarenta anos, após o pedido de outra dose de aguardente, disse ao trabalhador desempregado que não via problema em seu objetivo, mas que para isso ele precisava falar com os donos do maquinário que prestavam serviço a usina. Em meio ao que me pareceu corresponder a um misto de incerteza e receio em relação aos resultados, ou consequências dessa consulta, o trabalhador canavieiro revelou não ter experiência nesse tipo de trabalho e Ivã, o tratorista, procurando tranquilizá-lo, deixounos entender que o alcance de tal objetivo, dependia mais do tipo e da qualidade do contato mantido com a empresa prestadora de serviços.

Aquele diálogo me chamou a atenção, em particular, para a questão da terceirização do processo de mecanização no setor sucroalcooleiro e as dimensões do impacto que vinha se dando localmente. Foi então que ouvi do tratorista, antes que nos deixasse, pois ainda não havia dormido e já passasse das dez da manhã, um breve relato sobre o seu aprendizado e a pericia no trabalho como exemplificação de sua qualificação ao chegar, inclusive, a operar simultaneamente dois tratores no talhão de cana $^{24}$. Em um primeiro momento, diante de tal declaração, com relação aos seus feitos, uma das questões que despertou atenção, independente de ser verdadeira ou não, eram as relações de poder e dos seus sentidos que se encontravam implícitos na produção discursiva do tratorista ao enunciar relações de trabalho, atravessadas pelas relações pessoais, a “[...] estrutura social em que a hierarquia parece estar baseada na intimidade

\footnotetext{
${ }^{24}$ Observa (Selligman-Silva, 1996: 117) que no Brasil a expressão "trabalho qualificado", em oposição a "trabalho não qualificado", é utilizada para distinguir aqueles que perderam as qualidades que o recomendavam à consideração pública.
} 
social" - o "sabe com quem está falando?" 25 isto, ainda que nos dias da agricultura de precisão e emprego de tecnologia capaz de proporcionar a operacionalização simultânea, até mesmo, de mais de um trator no campo ${ }^{26}$. Fora do bar, ao retomar o diálogo com Dagão, tendo em conta a busca pelo registro de sua história de vida, procurei tornar aquela conversa a mais informal possível e acrescentar situações que pudessem oferecer informações a respeito de minha vida privada. Então, sem que houvesse planejado, estava me aproximando de uma técnica de pesquisa da psicologia social em que se examina a produção social dos sentidos a partir da conversa informal ${ }^{27}$.

De fato, do ponto de vista teórico-metodológico, a ideia de sentido ${ }^{28}$ apresentouse como uma palavra chave no que diz respeito à realização desta investigação e foi a partir da sua noção que busquei compreender o sofrimento social enquanto experiência social negativa. Logo, pensar sobre o sentido do sofrimento perpassaria por interpretar os elementos significativos dos atos empreendidos pelos agentes, tendo-se em conta a percepção que eles detinham acerca das suas práticas sociais.

A proposição acerca da impossibilidade de conhecer a realidade apartando-se o ver dos efeitos da percepção e do pensamento, por esta perspectiva, apresentar-se-ia intimamente vinculada à noção de sentido em sua relação com os significados a serem compreendidos pela investigação antropológica.

Nesse particular, a percepção enquanto fluxo de atividades integradas no tempoespaço e no movimento do corpo propõe, em específico, a ideia de que as faculdades do conhecimento sobre o modo como se compreende e se atribui sentido e significados às coisas estejam vinculados a atos cognitivos; portanto, olhar, ouvir e escrever, embora pudessem e possam ser tidos como algo trivial, entretanto, para as ciências sociais “[...] esses atos cognitivos [...] assumem, um caráter particular e de natureza epistêmica, uma vez que é com tais atos que logramos construir nosso saber" ${ }^{29}$.

O olhar antropológico exige, portanto, a sua domesticação, isto é, a domesticação teórica daquilo que se pode denominar como alteração do objeto pelo próprio modo de visualizá-lo, contudo essa refração não se mostra como um processo de mão única, em

\footnotetext{
25 (Da Matta, 1997: 192)

26 Empresa de tratores John Deere - trator no piloto automático - e a expressão "Agricultural Management Systems", ou "Soluções em Gerenciamento Agrícola" (Rocco, 2009: 4).

27 (Menegon,1999); “[...] quando uma pessoa chega à presença de outras, existe, em geral alguma razão que leve a atuar de forma a transmitir a elas a impressão que lhe interessa transmitir" (Goffman, 1995: 13).

${ }^{28}$ O sentido [...] não existe em si, mas sempre possui um objeto de referência. Sentido é a consciência de que existe uma relação entre as experiências (Berger e Luckmann, 2004: 15).

${ }^{29}$ (Cardoso de Oliveira, 2000: 18)
} 
virtude de nós seres humanos sermos observadores no observar - ponto central e, ao mesmo tempo, ponto de partida da reflexão sobre o que fazemos e como o fazemos ${ }^{30}$.

Por isso é que, na distância em que separa esta escrita e o momento em que me vi diante da resistência do trabalhador canavieiro em se apresentar como um possível informante - na tentativa em demovê-lo dessa posição -, a ideia da boa impressão se apresentou como um pensamento prático provindo de outras situações vividas e observadas. Foi então, a partir de meu estoque de referências, que lhe contei acerca das minhas vistorias nos talhões de cana, assim como a experiência em viajar com uma turma de trabalhadores, entre lembretes e desconfianças dos controladores da produção $^{31}$ e, sem dizer-lhe, pensava comigo, é claro, sobre a minha pouca habilidade nesse tipo de trabalho e as dificuldades relativas ao próprio objetivo a ser alcançado pelo investigador que se coloca no papel de observador total em relação aos cuidados com a manutenção do anonimato. Como resposta e tradução de meus pensamentos, ainda que em tom de desabafo e questionamento, Dagão contou-me ter deixado o corte de cana, mesmo sendo pai de dois filhos pequenos e que a sua mulher era quem se encontrava trabalhando naquela atividade. E lançando-me um desafio, antes de relatar o caso de um trabalhador que se mantinha em atividade - ainda que no momento das refeições - e o testemunho sobre o sofrimento de companheiros com caibras por toda parte do corpo ao final do dia, convidou-me ele a enfrentar o corte de cana caso quisesse, de fato, conhecer a condição de vida do trabalhador canavieiro. O meu papel ali na favela, reafirmei ao trabalhador, não era o de jornalista em busca do sofrimento como espetáculo ${ }^{32}$, embora os trabalhadores ao se encontrarem presos nas novas práticas de organização do trabalho vivessem como meros figurantes desse quadro cada vez mais competitivo, dado a maior e constante presença do "braço mecânico" nos canaviais. Este questionamento na forma de desafio sobre a minha presença na vila Santa Gertrudes, assim como o porquê de se privilegiar a temática do trabalho, a partir da reprodução da força de trabalho, ao invés do talhão de cana como lócus do universo em si do trabalho pareceu-me, entretanto, indicar a necessidade clara e indubitável de se ampliar as discussões e investigações em torno do desafio da escrita etnográfica, como ponte entre dois universos, em relação à "questão do trabalho" "fora do mundo do trabalho". Hermes, também morador na vila Santa Gertrudes, dias depois, revelar-me-ia

\footnotetext{
30 (Maturama, 2001)

31 (Fernandes, 2002)

${ }^{32}$ Sobre o sofrimento como espetáculo (Kleinman; Kleinman, 1997).
} 
a seguinte experiência sobre os efeitos da carga de trabalho e a sua violência personalizada:

Quando eu cortava cana cheguei [a] ir duas, três vez para o hospital. Dava fraqueza, né? Eu já cheguei até [mesmo a] ir trançando as perna [...]. [...] Você já viu o pessoal cortá cana? São cinco rua, né? A gente faz telefone, conta três e larga duas, aí que nem você tá trabalhando - três [a] quatro cabeças junto - [para] cortá cana boa ["cana em pé"]. Pegava cinco eito para cada um [desses, cinco ruas], então fazia telefone de cinco eito. Porque, logicamente, até a tarde tinha que tá pareado pô pessoal medi, porque senão você não [...] receber[ia]. Eu cheguei a cortá cana de joelho [...] quantas vezes para pareá o eito. Para terminá, ê [ainda que] de joelho no chão. Cana de pezinho, né? Porque quando dá câimbra, dá aqui no braço, na coxa, na sola do pé.

A primeira vez que ouvi falar sobre os excessos do trabalho e seus efeitos, a partir dos próprios trabalhadores canavieiros, ocorreu-me durante uma de nossas vistorias, em 2007, nos talhões e moradias de trabalhadores, provindos dos estados do Maranhão, Alagoas, Minas Gerais e Bahia, ao se instalarem em um núcleo habitacional no município de Queiroz na região de Marília - Estado de São Paulo. Foi nessa ocasião que ouvi a pronúncia da palavra borrado como uma primeira aproximação para designar o estado em que o trabalhador perde o controle físico e mental do próprio corpo em face da carga e do trabalho repetitivo ${ }^{33}$. A condição típica de sofrimento físico, enquanto padecimento do corpo em sua individuação e experiência social negativa, vinculada aos ditames do ritmo e do ciclo do trabalho repetitivo no talhão de cana. O estado de sofrimento na vida fora dos eitos dos canaviais ao se apresentar, em sua conexão, sob o aspecto da habitação - a casa, o barraco, o abrigo - constituir-se-ia em uma mercadoria de fundamental importância à reprodução da força de trabalho enquanto valor de uso e valor de troca, assim como, valor signo e de significação consubstanciados na hierarquização das relações de dominação personalizada ${ }^{34}$.

\footnotetext{
${ }^{33}$ Enquanto técnico do Grupo de Vigilância Sanitária, nesta vistoria ocorrida no final da safra de 2007, não atentei como deveria, portanto, à divisão entre trabalho e moradia enquanto ordem relacional capaz de tornar inteligível o poder e seu exercício em face de necessidades básicas de subsistência e com isso, a capacidade de compreender as dívidas materiais e simbólicas contraídas junto ao empreiteiro - o mediador principal entre a casa alugada, o trabalho, o usineiro e a rede de relações constituídas no novo endereço. Também não ponderei sobre o esgotamento, em face da fadiga contraída com a carga de trabalho realizada, pois, para permanecerem na empresa, admitiram alguns trabalhadores na época, far-seia necessário o corte de 10 toneladas de cana, diariamente, ainda que fosse frequente colher-se, até mesmo, de 15 a 20 toneladas e, em consequência, o trabalhador sentir mal estar: "ficava borrado", contraía câimbras em vários sítios do corpo. Ainda sobre fatiga e a exploração do trabalhador no corte de cana ver (Fascioli, 2009) e (Silva, 2009).

34 O conceito de dominação personalizada, (Palmeira, 1977); (Sigaud, 1979) e (Garcia Jr.,1989), corresponde à derivação do conceito de dominação tradicional, proposto por (Weber, 1991), com relação à probabilidade de encontrar-se obediência em um grupo de pessoas.
} 


\section{Metáfora do fracasso}

Neste sentido, aqueles que se apropriaram do espaço que veio ser designado como a favela da vila Santa Gertrudes, poder-se-ia dizer, projetaram sobre esse espaço o trabalho de quem não podia consumi-lo, do ponto de vista do mercado e do direito a alojamento na cidade. Com isso proporcionaram a produção de relações que envolviam e que se inscrevem no campo do poder simbólico não enquanto distinção positiva, mas como o que é invisível e que invizibilizado dever-se-ia manter, dado o modo como se deu e estabeleceu-se o consumo do espaço.

Sobre o episódio da ocupação do local e dos enfrentamentos com os poderes municipais, disse-me um antigo morador da vila Santa Gertrudes e ex-cortador de cana:

\footnotetext{
Umbelino: Quando eu ocupei o território tinha um rapaz, o Claudecir, o finado Claudecir [e dois irmãos]. Disse [me ele, então,] que [o terreno] era da Prefeitura [e que] eles já estavam ali.

Donizeti: E onde moravam eles?

Umbelino: Eles moravam aqui, na frente aqui.

Donizeti: Nesta beirada aqui?

Umbelino: Não. Esta rua não tinha, ele morava aqui [onde é o bar]. Daí eu morava [naquela época] ali, para o lado de baixo do asfalto... . Daí eu falei prá ele fazê um biongo aqui... Fiz um barraquinho ali [de] duas frentes e comecei... .

Donizeti: Então eram cinco moradores? E falavam que isso tudo era da Prefeitura?

Umbelino: É. Depois que era do doutor Mané... .Daí o doutor Mané cortou a água daqui.

Donizeti: Vocês tinham uma rede de água que chegava até aqui? Umbelino: Não. Era mina, era... .É. Aí vai daqui, vai dali [então] fui lá na Prefeitura pedi [para que religassem a] água e ele [o Prefeito] queria até me prender. Daí o engenheiro peitô eu no meio. E olha: ele ia-me batê lá [dentro] da Prefeitura, ou eu ia batê nele. Daí ele [o Prefeito Manoel] pegô [e falou:] "esta briga de vocês não compensa, ali não é da Prefeitura... é da Igreja [Católica]". Daí eu vim embora. E no outro dia fui no Palácio do Bispo e peguei [a autorização para religar] a água. Comprei uma [caixa] e puxei a água. No começo do [ano de] 83 [é] que puxei [a] água. [Eu e] esse meu compadre. Aqui não tinha nada, [e ele] me ajudô a fazê as valeta.

Donizeti: Então ficou nesta situação de desencontro de informações? Muitos falavam que o terreno era da Prefeitura e outros diziam que era da Igreja Católica?
}

A passagem da entrevista acima é importante para poder-se entender a enunciação sobre o modo como se deu a ocupação e apropriação de um território que, na verdade, encontrava-se sobre o domínio de algumas famílias instaladas e que, anteriormente à iniciativa do ex-cortador - embora este não soubesse precisar -, já houvesse sido ocupado, quando algumas famílias constituíram um grupamento de abrigos em terreno que seria reapropriado pela Prefeitura para que se construíssem os primeiros conjuntos habitacionais no bairro Porto Belo. Esse fato leva a entender que as famílias de trabalhadores, com o final do colonato e do sistema de parceria, continuassem - desde a 
década de 1970 - a rumar para a cidade e, não encontrando alojamento, passassem a se apropriar de territórios que se apresentavam como áreas de risco e vulnerabilidade, em face do desnível topográfico, degradação ambiental e inundações com as águas das chuvas. A política habitacional em Jacarezinho em face das três décadas subsequentes, período de apropriação, instalação e incorporação do território da vila Santa Gertrudes, poucas ações desenvolveu para minorar as dificuldades de acesso à moradia, situação que se agravou ainda mais com a expulsão das famílias de trabalhadores das antigas seções de usina no final dos anos de 1980. Assim, o território se tornou favela enquanto projeção da conduta de determinados seres humanos sobre o espaço, bem como, solução aos interesses políticos e econômicos ao capitalizarem-se anseios eleitorais e lucros com o não pagamento de indenizações aos trabalhadores.

A apropriação do território realizada pelos primeiros moradores, ao que parece, obedeceu à ação da busca pela instalação de abrigos em locais menos suscetíveis a inundações, em virtude do declive do terreno ocupado. O bar e a casa de Umbelino, por exemplo, estavam localizados na parte mais alta do terreno e, enquanto marco de referência por seu "estado habitável" - na entrada principal da favela -, levou-me a pensar que as construções nesse perímetro tinham obedecido a ordem de chegada e, por isso, em um primeiro momento, serem eles os "os estabelecidos" no lugar. Independente do espaço físico, uma das coisas que determina a posição ocupada no território e que só aos poucos fui dando-me conta, era a de que o espaço da Vila Santa Gertrudes se encontrava dividido e hierarquizado por outras distinções e redes sociais de relações, pois, o local na sua forma visível, ocultava relações distanciadas que determinaram sua natureza. A "descoberta" só veio ocorrer no momento em que uma das moradoras me contou, instalada na área de maior declive no terreno, que não gostaria de sair dali mesmo com as inundações e as condições precárias, para não dizer inabitáveis do abrigo. Ainda segundo esta moradora, as novas casas ${ }^{35}$, por melhores que elas fossem, ofereceriam maior exposição à violência devido à facilidade do contato dos filhos com o consumo de drogas. A proximidade das ruas, o pequeno quintal sem

\footnotetext{
35 As novas casas, formando um novo conjunto habitacional, não ficavam distantes da vila Santa Gertrudes. O projeto do Município, orçado para construção de 36 casas em 2007, tinha um custo de 730.813,19 reais, mas foi ampliado para o valor de 4 milhões. Em sua entrega, em 2010, conforme o vídeo promocional, outros projetos como posto de saúde, creche, conjunto poliesportivo estariam condicionados, em sua construção, ao financiamento do Governo Federal - Programa de Aceleração do Crescimento - PAC 2 . Além desse projeto das casas, a área fundiária apropriada da Vila Santa Gertrudes passaria a ser regularizada com o título de posse aos moradores que não tiveram suas casas removidas.
} 
árvores e isso tudo, principalmente, em face das "biqueiras" "36 , já instaladas, no conjunto

habitacional a ser entregue no ano seguinte a esta investigação. Em minhas explorações

nos trilhos da vila Santa Gertrudes anotei, quando da entrevista com esta moradora, o

seguinte relato em meu caderno de campo:

Saímos por volta das $12 \mathrm{~h} 30$. Anteriormente disse a Jair que tinha interesse em conhecer as vielas e os trilhos que davam acesso aos abrigos dos moradores que ficam mais afastados das ruas. Seguimos em sentido oeste, os hidrômetros e as caixas com medidores de energia estão localizados logo na entrada do trilho. Sorrindo ao se lembrar do local, Jair disse-me ter feito sexo várias vezes naquele lugar. O caminho é coberto com árvores ornamentais e frutíferas, a distância entre os seus flancos tem no máximo de dois a três metros. Os abrigos estão dispostos, um ao lado dos outros e as distâncias são guardadas por fios de arame, lascas de bambu, plantas que se transformam em uma espécie de cerca viva, ou mesmo com lona de plástico. No interior de um dos abrigos, a dona da casa, uma senhora negra com cerca de 35 anos, contou-me que morava ali há, aproximadamente dez anos com o seu marido e quatro filhos. $\mathrm{O}$ abrigo, construído em alvenaria, era coberto com telha de amianto de fina espessura - do mesmo tipo que cobre o meu alojamento e de meus vizinhos. Nele havia, conforme a mulher, vários furos graças à prática de se jogar pedra e outros objetos nos telhados. O marido era cortador de cana e os filhos estavam na faixa de oito a quatorze anos - três meninos adolescentes e uma menina que tinha atingido a puberdade. A casa, como admitiu, era muito precária, mas mesmo assim, oferecia mais espaço que aquelas que seriam entregues pela Prefeitura e, ainda que ali não mantivesse segurança, em face da violência dos "estabelecidos", a mulher admitiu guardar distância de episódios, cenas, ou situações que a esses se reportavam. Mesmo assim, contou-me que, um dia desses, o filho mais velho foi agredido com uma tapa no rosto desferido por um menino mais novo, no momento em que ela pediu para que fosse até o bar. O marido, quando chegou do trabalho, informado do ocorrido saiu para saber sobre o que havia acontecido e foi surpreendido ao encontrar o garoto que bateu em seu filho, postado com uma arma na cintura. Ao se referir ao trilho em que estávamos, a mulher confessou-me evitar passar por aquele caminho e seguir outro, ao lado, por ter mais vizinhos e menos mato. Ao cair da noite, tinha como rotina, o hábito de fechar todas as janelas e portas já que o uso de drogas e as práticas sexuais eram constantes naquele local. Com relação aos serviços de água, devido a sua casa manter-se distante da rua, o serviço da companhia costumava cobrar taxas elevadas em relação ao consumo e, muitas vezes, o fornecimento era suspenso em consequência dos talões não chegarem até a sua casa. Não havia caixa de correio para entrega de cartas, por isso permaneciam depositados nos cavaletes na entrada do trilho. As taxas variavam de 40 a 140 reais e mesmo que existisse a possibilidade de se cadastrar no programa oferecido para pagar menos pelo serviço municipal de abastecimento, ela não conseguiria porque permanecia continuamente em dívida. Um dos requisitos básicos para conseguir se inscrever no programa era estar com o pagamento atualizado na companhia de água. Em sua casa, a única pessoa que trabalhava fora era o seu marido. Ela já havia trabalhado no corte de cana, mas devido à doença - sofria de trombose - encontrava-se impossibilitada de continuar. Disse-me ainda que era evangélica, mas que na sua igreja - Congregação Cristã - não havia a prática da busca por soluções de problemas que afligissem os fiéis em situações como as de pagamento de taxas de luz e água. Eram problemas comuns, como admitiu, mas os fiéis os resolviam individualmente e, sendo assim, o que mais faziam era fornecer cestas básicas. As novas casas, como também observou a mulher, ainda que fossem melhores, os seus filhos - do ponto de vista da violência e perigos da rua - estariam mais suscetíveis aos efeitos da nova localidade, pois ali é que estariam instaladas as

${ }^{36}$ Ao que tudo indica, "biqueiras" correspondem aos locais de trânsito mantidos entre vendedores e clientes no comércio de drogas a varejo. 
"biqueiras". O pequeno quintal, em proximidade das ruas, não iria mantê-los em casa.

Se a favela apresenta-se como território destinado a gentes que não podem consumir outro espaço que permita a distinção social, essa se tornaria a própria metáfora dos fracassados, dada a distância e o gosto comum pelo desvio, mas se assim o fosse, como interpretar as anotações de meu caderno de campo citadas anteriormente?

Nesta pesquisa, quando se sobrepõe os dados referentes ao número de favelas e as notificações de agravos relativos à saúde dos trabalhadores ${ }^{37}$, o que se verifica é que no Norte Pioneiro estas condições de moradia se justapõem à subnotificação do dano sofrido e relacionado ao ambiente de trabalho agrocanavieiro, bem como, a descrição acima proporciona o entendimento de que há uma simultaneidade de eventos a contribuir para a experiência social negativa, por isso os sofredores não experimentarem apenas dois problemas no máximo, como quer alguns ${ }^{38}$. Em outras palavras, a não apresentação ou disposição de dados por ramo de produção, assim como o baixíssimo número de notificações de agravos relacionados à saúde do trabalhador, por sedes regionais de saúde no Estado do Paraná - onde há instalação de destilarias, usinas e favelas -, permite pensar o quanto o poder político- econômico e institucional faz aos homens e às mulheres e estes a si mesmos ao viverem o fluxo da experiência do sofrimento social. Ou seja, muito embora a colheita de cana manual propicie situações indicativas quanto à probabilidade de ocorrência de eventos, entre outros, relacionados aos agravos e distúrbios osteomusculares, no entanto, conforme os dados estatísticos oficiais de $2011^{39}$, esses acontecimentos em sua maior parte teria como procedência às regiões de Curitiba e de Londrina. Curiosamente, ao contrário do que se possa pensar, na região da capital do Estado do Paraná não há produção de cana-de-açúcar e, tão pouco, agroindústrias instaladas. Já no caso da região de Londrina, ainda que tenha ocorrido registro de agravos relacionados à saúde dos trabalhadores, importante a perceber, é que desde 2006 estava a ocorrer, não só nesta como em todo norte do Estado, uma franca expansão da produção canavieira, sendo prevista inclusive, pela Associação de Produtores de Álcool e Açúcar do Estado do Paraná - ALCOPAR -, a necessidade de se trazer trabalhadores de outras cidades, bem como de outros

\footnotetext{
${ }^{37}$ CEST/PR - 2011; PEHIS, 2010

38 (Kleinman; Das; Lock, 1997)

${ }^{39} \mathrm{CEST} / \mathrm{PR}-2011$
} 
municípios da região Nordeste do país ${ }^{40}$. O que todos empiricamente sabiam e sabem, ao tratar dos estudos sobre morbidade e mortalidade em epidemiologia, é "[...] que o adoecer e morrer é desigual e se distribui geograficamente, segundo as classes e segmentos sociais, renda e trabalho" 41

\section{Conclusão}

O que a escrita biográfica sobre o trabalhador canavieiro permite entender é que nos talhões de cana impôs-se um novo ritmo de organização do trabalho - a disputa entre o "braço mecânico" e o braço humano. Um tipo de trabalho, historicamente precário, em um mundo, ao final dos anos de 1990, cada vez mais sem trabalho e de invalidação social como atributo às relações de dominação expressas, material e simbolicamente, em eventos como agravos relacionados à saúde: mortes anunciadas e sucessão de experiências sociais negativas dentro e fora dos talhões de cana, situações como aquelas que foram apresentadas no relato de campo acima e que tendem a ser observadas como campos em separados de investigação e intervenção.

\section{Referências}

BERGER, Peter; LUCKMANN, Thomas. Tradução Edgar Orth. Modernidade, pluralismo e crise de sentido. Petrópolis: Vozes, 2004.

BOURDIEU, Pierre. El sentido prático. Tradução de Ariel Dilon.Buenos Aires: Siglo XXI Editores, 2007

Cosas dichas. 2.d. Tradução de Margarida Mizrarji. Barcelona: Gedsa, 2000.

CARDOSO de OLIVEIRA, Roberto. O trabalho do antropólogo. 2. ed. São Paulo; Paralelo 15, Editora UNESP, 2000.

CICOUREL, Aaron. Teoria e método em pesquisa de campo. Tradução Alba Zaluar Guimarães. in: GUIMARÃES, Alba Zaluar. Desvendando máscaras sociais. Rio de Janeiro: Francisco Alves, 1975.

GIDDENS, Anthony. A constituição da sociedade. 2. ed. Tradução de Álvaro Cabral. São Paulo: Martins Fontes, 2003.

CLIFFORD, James. A experiência etnográfica: antropologia e literatura no século XX. 2. ed. Tradução Patrícia Farias. Rio de Janeiro: Editora UFRJ, 2002. COMPANHIA DE HABITAÇÃO DO PARANÁ. Apresentação seminários PEHIS, 2010. Disponível em:

\footnotetext{
${ }^{40}$ Conforme (Zanchet, 2008), a expansão canavieira em 2006 se deu nas Mesorregiões Noroeste (42,9\%) e Norte Central (30,4\%), sendo que o Norte Pioneiro permaneceu com 17,9\% do total da produção no Paraná. Para esse mesmo período (Maia e Lima, 2007)

${ }^{41}$ (Ribeiro, 1997: 17)
} 
<http://www.cohapar.pr.gov.br/modules/conteudo/conteudo.php?conteudo=136. $>$ Acesso: 18 mar. 2012.

COULON, Alain. Etnomedologia.Tradução Ephraim Ferreira Alves. Petrópolis, RJ: Vozes. 1995.

DA MATTA, Roberto. O ofício de etnólogo, ou como ter "anthropological blues". In: NUNES, Edson de Oliveira (Org.). A aventura sociológica: objetividade, paixão, improviso e método na pesquisa social. Rio de Janeiro: Zahar Editores, 1978. Carnavais, malandros e heróis: para uma sociologia do dilema brasileiro. 6. ed. Rio de Janeiro: Rocco, 1997. EDUARDO, Marcos Faria. Território, trabalho e poder: por uma geografia relacional. Campo Território. São Paulo, v. 1, n. 2, p. 173-195, ago. 2006.

FACIOLI, Irmã Inês. et al. Vozes do eito. Guariba-SP: Eco Letras, 2009.

FERNANDES, Antonio Donizeti. Da questão do trabalho fora do "mundo do trabalho": canavieiros e a experiência social do sofrimento. 201 2. 318 f. Tese (Doutorado em Ciências Sociais) - Faculdade de Filosofia e Ciências, Universidade Estadual Paulista, São Paulo, 2012. Disponível em: < http://www.marilia.unesp.br/\#!/pos-graduacao/mestrado-edoutorado/ciencias- sociais/teses />. Acesso em 16 de mai. 2013

A aventura do risco entre os trabalhadores do corte de cana-de-açúcar. $2002.245 \mathrm{f}$. Dissertação (Mestrado em Ciências Sociais)-Faculdade de Filosofia e Ciências, Universidade Estadual Paulista, São Paulo, 2002. Disponível em: <http://www.athena.biblioteca.unesp.br/exlibris/bd/bma/33004110042P8/2002/fernande s_ad_me_mar.pdf>. Acesso em: 16 mai. 2013.

FOOTE-WHYTE, Willian. Treinando a observação participante. Tradução Claudia Menezes in: GUIMARÃES, Alba Zaluar. Desvendando máscaras sociais. Rio de Janeiro: Francisco Alves, 1975.

GARCIA JÚNIOR, Afrânio. O sul. Caminho do roçado. São Paulo: Marco Zero; Brasília: Editora da Universidade de Brasília, 1989. GIDDENS, Anthony. A constituição da sociedade. 2. ed. Tradução de Álvaro Cabral. São Paulo: Martins Fontes, 2003.

GOFFMAN, Erving. A representação do Eu na vida cotidiana. 5. ed. Tradução Maria Célia Santos Raposo. Petrópolis: Vozes, 1992.

JACQUES, Paola Berenstein. A estética da ginga: a arquitetura das favelas através da obra de Hélio Oiticica. 3. Ed. Salvador: EDUFBA, 2007.

JODOLET, Denise. Experiência e representações sociais. Tradução Maria Suzana de Stéfano Menin. In: MENIN, de Estefano S. Maria et. al. Experiência e representação social: questões teóricas e metodológicas. São Paulo: Casa do psicólogo, 2005. p. 23- 55.

KLEINMAN, Arthur; DAS, Veena; LOCK, Margaret. Social suffering. Los Angeles: University of California Press, Berkeley, 1997.p. XI- XXVII.

KLEINMAN, Arthur; KLEINMAN, Joan. The appeal of experience; the dismay of Images: cultural appropriations of suffering in our times. In: KLEINMAN, Arthur; DAS, Veena; LOCK, Margaret. Social suffering Los Angeles: University of California Press, Berkeley, 1997. p. 1-23.

KLEINMAN, Arthur. Writing aint the margin: discurse between antropology and medicine. California: University of California Press, 1995. 
LE BRETON, David. Antropología del dolor. Traduccón Daniel Alcoba. Barcelona: Editorial Seix Biarral, 1999.

LEBARÓN, Fréderic. La sociologie de A à Z. Paris: Dumon, 2009.

MAIA, Samantha; LIMA, Marli. Etanol provoca migração de pessoal entre setores e regiões. Valor Econômico, 2007. Disponível em: <http://www2.senado.gov.br/bdsf/item/id/14997>. Acesso: 18 mar. 2012.

MATURAMA, Humberto. Cognição, ciência e vida cotidiana. Tradução Cristina Magro e Vitor Paredes. Belo Horizonte: Editora UFMG, 2001.

MENEGON, Vera Mincoff. Por que jogar conversa fora? Pesquisando no cotidiano. In: SPINK, Marie Jane (Org.). Práticas discursivas e produções de sentidos no cotidiano: aproximações teóricas e metodológicas. São Paulo: Cortez, 1999.

ORTIZ, Renato (org.). A procura de uma sociologia da prática. In: BOURDIEU, Pierre. Sociologia. Trad. Paula Monteiro e Alícia Auzmendi. São Paulo: Ática,1983.

PALMEIRA, Moacir. Casa e trabalho: nota sobre as relações sociais na plantation tradicional. Contraponto, Rio de Janeiro, n.2, 1977. p. 103 -114. PARANÁ. CENTRO ESTADUAL DE SAÚDE DO TRABALHADOR. Política estadual de atenção integral à saúde do trabalhador no Paraná, 2011. Disponível em <http://www.saude.pr.gov.br/modules/conteudo/conteudo.php?conteudo=1516>. Acesso em 18 mar. 2012.

RAFFESTIN, Claude. Por uma geografia do poder. Tradução de Maria Cecília França. São Paulo: Ática, 2011.

RIBEIRO, Herval Pina. LER: conhecimento, práticas e movimentos sociais. Faculdade de Saúde Pública - USP, São Paulo, 1997.

ROCCO, Giancarlo Coscelli. Relatório final de estágio: benefícios obitidos pelo uso da agricultura de precisão. Disponível em: http://www.ler.esalq.usp.br/download/gmap/estagio/Rocco.pdf. Acesso: 13 mai. 2012.

SCHUTZ, Alfred. Fenomenologia e relações sociais. Tradução de Angela Melin. Rio de Janeiro: Zahar, 1979. Fenomenología del mundo social. Introducción a la sociología compreensiva. Traducción de Eduardo J. Prieto. Buenos Aires: Paidos, 1972. SELIGMANN-

SILVA, Edith. Desgaste mental no trabalho dominado. Rio de Janeiro: Editora UFRJ, 1994.

SIGAULD, Lygia. Os clandestinos e os direitos: estudo sobre os trabalhadores da cana-deaçúcar de Pernambuco. São Paulo: Duas Cidades, 1979.

SILVA, Maria Aparecida Moraes. Introdução: a barbárie do i-mundo eito dos canaviais paulista. In: FACIOLI, Irmã Inês. et al. Vozes do eito. Guariba-SP: Eco Letras, 2009.

SPINK, Maria Jane; MEDRADO, Benedito. Produção de sentidos no cotidiano: uma abordagem teórico-metodológico para análise das práticas discursivas. In: Práticas discursivas e produção de sentidos no cotidiano: aproximações teóricas e metodológicas. São Paulo Cortez, 1999.

SMELSER, Neil J. Problematics of sociology lectures. Los angeles: University of Califonia Press, 1997. 
WEBER, Max. Economia e sociedade: fundamentos da sociologia compreensiva. Tradução Regis Barbosa e Karen Elsabe Barbosa. Brasília, DF: Editora Universidade de Brasília, 1991, v.1.,[ 2004 v.2]

ZANCHET, Maria Saléte. Características das ocupações na agropecuária paranaense. Curitiba: IPARDES, 2008.

Recebido em: 30/07/2013

Aprovado em: 07/08/2013 